\title{
APLICAÇÃO DA ANÁLISE POR ENVOLTÓRIA DE DADOS UTILIZANDO VARIÁVEIS CONTÁBEIS
}

SILVIA PEREIRA DE CASTRO CASA NOVA

Doutora em Controladoria e Contabilidade pela Universidade de São Paulo

Professora da Universidade de São Paulo

E-mail: silvianova@usp.br
ARIOVALDO DOS SANTOS

Doutor em Controladoria e Contabilidade pela Universidade de São Paulo

Professor Titular da Universidade de São Paulo E-mail: arisanto@usp.br

\section{Resumo}

Esta pesquisa tem como objetivo apresentar a aplicação dos pressupostos do modelo DEA na avaliação dos níveis de eficiência das empresas brasileiras, a partir de variáveis contábeis. Tendo em vista a mudança de paradigma da pesquisa contábil nas últimas décadas para a abordagem positiva, torna-se relevante a possibilidade de utilização de métodos quantitativos como instrumento metodológico para testar hipóteses sobre os desempenhos econômico, financeiro e operacional das empresas. Para a avaliação dos pressupostos, como forma de exemplificar a aplicação do método, utilizou-se dados sobre faturamento, número de funcionários e valor total do ativo de companhias do setor elétrico e estruturou-se um exemplo como forma de exemplificar a aplicação do método. De acordo com as simulações realizadas, foi possível identificar o nível de eficiência de uma empresa em relação às demais. A técnica possibilitou traçar uma fronteira de eficiência para o conjunto de empresas analisadas e observar o posicionamento de cada uma em relação a essa fronteira, além de permitir a identificação das ações que a companhia considerada ineficiente deveria realizar para atingir a fronteira de eficiência ou o nível de eficiência da empresa-referência.

Palavras-chave: análise por envoltória de dados; Contabilidade; métodos quantitativos aplicados à Contabilidade.

\section{Abstract}

This research has as objective to present the application of DEA model objectives in efficiency levels evaluation on Brazilian companies, based on accounting variables. Based on the accounting research paradigm change in the last decades into positive approach, the possibility of using quantitative methods as a methodological instrument to test hypothesis about companies' economic, financial and operational performance becomes relevant. To evaluate the objectives, as a way to exemplify the method application, there had been used data about billing, number of workers, and assets total value of companies from electric sector. An example as a way of exemplifying the method application was also developed. According to the simulations taken, it was possible to identify the level of efficiency of a company in relation to the others. The technique made it possible to draw a line of efficiency for the set of companies analyzed and to observe the position of each one of them in relation to this line. Besides, it also permitted the identification of the actions the companies considered inefficient should develop in order to reach efficiency line or to reach the level of reference-company line.

Key words: data envelopment analysis, Accounting, quantitative methods applied to Accounting. 


\section{INTRODUÇÃO}

A Contabilidade representa a linguagem dos negócios, representando, portanto, o meio de comunicação das empresas com a sociedade que as cerca. Tratando-se de uma quantidade variada de usuários de tais informações, não é possível atender a todos igualmente; neste sentido, as companhias colocam à disposição uma gama variada de informações econômico-financeiras, as quais serão conjugadas de forma distinta para atender as diferentes necessidades relacionadas ao desempenho, à situação patrimonial, entre outras.

As técnicas de análises de balanços são antigas e têm sido largamente utilizadas para a avaliação de resultados passados e projeções de situações futuras. Segundo Matarazzo (1995), data de 1919 um modelo de análise de balanços com base em índices; Altman (1968) publicou um trabalho de análise de demonstrações contábeis com base em métodos quantitativos; no Brasil, Kanitz (1974) desenvolveu o que denominou "termômetro da insolvência" para previsão de falência de empresas. Mais recentemente, a aplicação de métodos quantitativos para análises das informações contábeis, tais como análise de regressão, análise fatorial e discriminante, redes neurais têm sido de larga aplicação. $E$, uma delas, é a Análise por Envoltória de Dados, do inglês Data Envelopment Analysis (DEA), que será aqui explorada.

No presente estudo, pretende-se apresentar um exemplo de sua aplicação para avaliação do nível de eficiência das empresas com base em variáveis contábeis. A justificativa desta pesquisa está relacionada à mudança do paradigma de pesquisa contábil de uma vertente normativa para uma vertente positiva. Assim, a aplicação de ferramentas matemáticas e estatísticas constitui um meio para avaliação das hipóteses subjacentes à teoria.

A estratégia metodológica adotada nesta pesquisa é a de um estudo empírico analítico, em que os dados selecionados para simulações realizadas foram obtidos a partir das maiores empresas brasileiras do setor de energia elétrica.

O trabalho encontra-se estruturado em cinco itens, incluindo esta Introdução. Inicialmente são discutidos os aspectos da teoria contábil e suas inter-relações com as Ciências Exatas. Na seqüência, são abordados os pressupostos teóricos sobre a aplicação da DEA. No quarto item, apresentam-se as simulações obtidas na aplicação do modelo a empresas do setor elétrico. E, por fim, são arroladas as considerações finais.

\section{FUNDAMENTAÇÃO TEÓRICA}

A Ciência Contábil está tão próxima dos números que muitos se aventuram a classificá-la como Ciência Exata. Seu nascimento esteve umbilicalmente ligado ao nascimento da Álgebra, conduzido também pelas mãos do monge Luca Paccioli. Bernstein (1997 p. 41) explicita esse surgimento conjunto, ao tratar dos avanços que o Renascimento trouxe ao desenvolvimento da Álgebra e da concepção moderna de risco:

O estímulo de grande parte desse interesse data de 1494, com a publicação de um notável livro de um monge franciscano chamado Luca Paccioli. Paccioli nasceu em torno de 1445, em Borgo de San Sepulcro, cidade natal de Piero della Francesca. [...]

A obra-prima de Paccioli, Summa de arithmetic, geometria et proporcionalità (as obras acadêmicas mais sérias ainda eram escritas em latim), apareceu em 1494. 
Escrito em elogio à 'imensa abstração e sutileza da matemática', a Summa reconhece a dívida de Paccioli para com o Líber abaci, de Fibonacci, elaborado trezentos anos antes. A Summa fixa princípios de álgebra e contém todas as tabuadas de multiplicação até $60 \times 60$ - um recurso útil em uma época em que a imprensa disseminava o uso do novo sistema de numeração.

Uma das contribuições mais notáveis do livro foi sua apresentação da contabilidade por partidas dobradas. Embora não fosse inventada por Paccioli, recebeu o mais extenso tratamento até então. A noção de contabilidade por partidas dobradas já se esboçara no Líber abaci, de Fibonacci, e aparecera em um livro publicado em torno de 1305 pela filial londrina de uma empresa italiana. Qualquer que seja sua origem, essa inovação revolucionária teve importantes conseqüências econômicas, comparáveis à descoberta da máquina a vapor trezentos anos depois.

É interessante a fixação de uma mesma data de nascimento para a Contabilidade e para a Álgebra. É mais interessante, ainda, retornar aos pontos de contato entre duas ciências que caminharam por trilhas distintas. Uma creditada às ciências exatas e puras. Outra às ciências humanas (ou sociais) e aplicadas. Ou não será tão simples assim?

As classificações dos ramos da Ciência preocupam os estudiosos da Metodologia Científica e os pesquisadores de cada campo de conhecimento, sem que se chegue, porém, a conclusões definitivas.

Martins (1994, p. 89) salienta os aspectos humanos e sociais que envolvem a Contabilidade e a natureza subjetiva do processo de mensuração, registro e reconhecimento de transações contábeis. E declara: "Que Sorte: a Contabilidade não é uma Ciência Exata". É também a resposta de ludícibus (1997, p. 69) à pergunta: Será a Contabilidade uma Ciência Exata?

\begin{abstract}
Apesar dessas dificuldades, hoje é geral a aceitação de alguns campos de conhecimento social como ciências, principalmente quanto mais for possível introduzir mensuração nelas. Nesse aspecto, a Economia já foi citada como a mais quantificável das ciências sociais. Com mais razão ainda, a Contabilidade o seria, dada a equação patrimonial básica, levando alguns até a considerá-la como ciência exata, pasmem! A Contabilidade, todavia, mesmo na aplicação da identidade fundamental, está longe de ser exata, quando pensamos nas aproximações, estimativas que devemos fazer para avaliar ativos e passivos, para estimar a despesa de depreciação, etc. Nem no sentido mensuracional a Contabilidade é exata. Ainda mais quando verificamos que serve para a tomada decisão de agentes econômicos (sociais), que alteram o status quo da sociedade. Assim, concluiu-se que, se ciência é, certamente a Contabilidade não é ciência exata.
\end{abstract}

Entretanto, é desejável que se busque uma aproximação da Contabilidade com a pesquisa quantitativa, uma vez que lida com uma grande massa de dados, melhor compreendida com a utilização de parametrização, estatística e/ou determinística.

Igualmente, a utilização de métodos quantitativos tem como função acrescentar uma capacidade preditiva ou prospectiva à Contabilidade.

Percebe-se, atualmente, nas Ciências Sociais, e não apenas na Ciência Contábil, uma aplicação crescente de Métodos Quantitativos. Isso se deve, em parte, às facilidades introduzidas pela revolução tecnológica recente no tratamento estatístico de informações.

Para ter noção desse impacto na pesquisa contábil, pode-se recorrer a uma avaliação da experiência de Melhores e Maiores, edição especial da Revista Exame, que anualmente avalia o desempenho das empresas brasileiras e elege a melhor empresa com base em suas informações contábeis. Na abertura de sua $1^{\text {a }}$. Edição ${ }^{1}$ em 1974 fica clara essa restrição. Conta-se que, para a elaboração do estudo, "durante oito meses - a partir

\footnotetext{
${ }^{1} \mathrm{Na}$ época, com a denominação de BRASIL EM EXAME.
} 
de 1973 - foram examinados mais de 10 mil balanços de empresas" (Fonte). Foi selecionado então um conjunto de 1.600 balanços para análise em profundidade.

Os dados recolhidos de cada balanço foram passados para cartões de computador, de modo a permitir o processamento eletrônico - único meio de tornar viável um empreendimento de tal porte, em que foram efetuados cerca de 18 milhões de cálculos e consumidas 212 horas de computador. (EXAME, 1974, p. 4)

Hoje, trabalho semelhante, com cerca de 1.200 empresas e dados para 2 anos ou mais, poderia ser executado em uma planilha de cálculo como Microsoft Excel $®$ em poucos minutos. Análises estatísticas sofisticadas, como Regressão Linear e Análise Discriminante, seriam implementadas para esse conjunto de dados. É nesse contexto que se torna oportuno analisar as possibilidades de aplicação da Análise Envoltória de Dados à Contabilidade.

\section{DAS BASES DA ANÁLISE POR ENVOLTÓRIA DE DADOS}

O histórico de desenvolvimento do método de Análise Envoltória de Dados se inicia com a tese de doutoramento de Edwardo Rhodes, apresentada à Carnegie Mellon University em 1978, sob orientação de W. W. COOPER.

O objetivo da pesquisa era avaliar os resultados de um programa de acompanhamento de estudantes carentes, instituído em escolas públicas americanas, com o apoio do governo federal. A idéia central era comparar o desempenho de um conjunto de alunos de escolas que participavam, com o de alunos de escolas que não aderiram ao programa. A performance dos alunos era medida em termos de produtos definidos, como, por exemplo, "aumento da auto-estima em crianças carentes" (medida por testes psicológicos) e insumos como "tempo gasto pela mãe em exercícios de leitura com sua criança".

Essa tentativa de estimação da eficiência técnica de escolas, com base em múltiplos insumos e produtos, resultou na formulação do Modelo CCR (abreviatura de Charnes, Cooper e Rhodes, sobrenomes de seus autores) de Análise Envoltória de Dados e com a publicação do primeiro artigo no European Journal of Operations Research em 1978.

0 modelo utiliza o método de otimização de programação matemática para, partindo da medida de eficiência técnica em casos de único produto/insumo proposta por Farrel em 1957, desenvolver um modelo que atenda a casos com múltiplos produtos/insumos, com a construção de um único produto "virtual” e um único insumo "virtual” (CHARNES, COOPER, LEWIN \& SEIFORD, 1997, p. 3).

A formulação matemática do Modelo CCR original pode ser assim apresentada (CERETTA \& NIEDERAUER, 2000, p. 3):

Considere-se $N$ empresas produzindo $m$ quantidades de produtos y a partir de $n$ quantidades de insumos $x$. Uma empresa $k$ qualquer produz $y_{r k}$ quantidades de produtos com a utilização de $x_{i k}$ quantidades de insumos. 0 objetivo da DEA é encontrar o máximo indicador de eficiência $h_{k}$ onde $u_{r}$ é o peso específico a ser encontrado para um produto $r$ e $v_{i}$ o peso específico de cada insumo $i$. 
Maximizar $h_{k}=\sum_{r=1}^{s} u_{r} y_{r k}$,

sujeito a

$\sum_{r=1}^{m} u_{r} y_{r j}-\sum_{i=1}^{n} v_{i} x_{i j} \leq 0$

$\sum_{i=1}^{n} v_{i} x_{i k}=1$

$u_{r}, v_{i} \geq 0$

$y_{r}=$ quantidade de produto $r ; \quad x_{i}=$ quantidade de insumo $i$;

$u, v=$ pesos

$r=1, \ldots, m ; i=1, \ldots, n ; j=1, \ldots, N$

Assim, tendo-se um grupo de empresas e seu plano de produção realizado, pode-se construir uma curva de produção que se constitui, então, no conjunto de produção revelado. Resolvendo-se o problema de programação linear (PPL) proposto para cada uma das empresas do grupo, podem ser identificadas aquelas empresas cujo plano de produção, dados os pesos determinados para suas quantidades de produtos e insumos, não pode ser superado pelo plano de nenhuma outra empresa. Esta empresa é dita eficiente e torna-se referência para as demais. Assim, resolvendo-se sucessivamente o PPL para cada uma das empresas que compõem o grupo considerado serão determinadas quais empresas são relativamente eficientes.

Se os planos de produção de cada empresa forem pontos em um gráfico, obtém-se uma representação semelhante à da Figura 1.

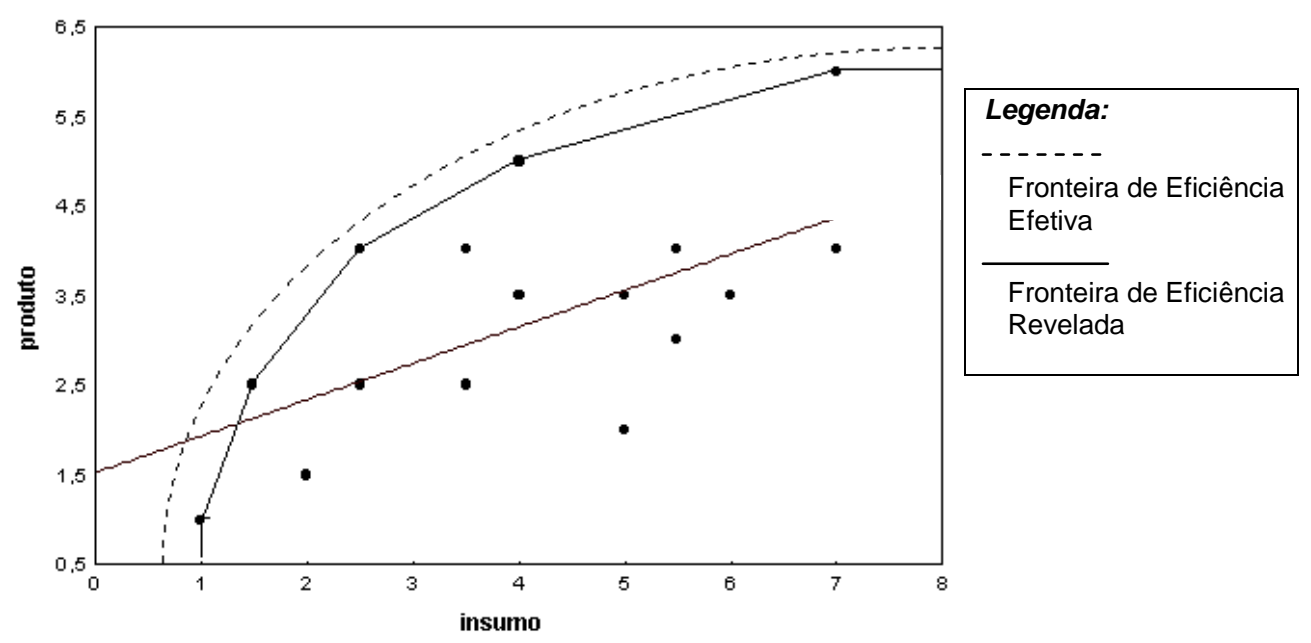

Figura 1 - Análise DEA para um conjunto de empresas

Os pontos na figura são os planos de produção realizados pelas empresas em análise. A curva de produção reúne as empresas cujo plano de produção não foi superado por nenhuma outra, considerando os pesos determinados pela resolução do PPL para suas quantidades de insumos e produtos. É a chamada Fronteira de Eficiência. Ressalte-se que 
é a fronteira revelada pelo conjunto de produção considerado, ou seja, considerando-se aquele grupo de empresas. Qualquer empresa que seja incluída ou excluída da análise modifica o conjunto de produção e, portanto, a fronteira.

Outro ponto a ser ressaltado é que a fronteira eficiente revelada pode não ser a fronteira eficiente efetiva. Isso acontece se as empresas em análise estiverem operando sob condições distantes do livre mercado. Ou seja, em economias protegidas ou setores monopolistas, a fronteira eficiente estaria revelando a eficiência relativa, considerando essas condições de operação, e existiria outra fronteira, indicada na Figura 1 pela curva pontilhada, que se constituiria no conjunto de produção ideal. Por isso, diz-se de eficiência relativa ou Pareto eficientes. As empresas eficientes seriam mais corretamente definidas como pontos Pareto não-dominados.

Os pontos abaixo da curva de eficiência representam planos de produção que foram “dominados" e estão "envolvidos" pela operação das empresas eficientes. Para cada um deles há uma opção, representada pelas quantidades praticadas ou por uma combinação convexa das quantidades praticadas pelas unidades de referência.

Nas palavras de Carlos HUMES Jr. (2001, p. xx): “DEA diz que uma condição necessária para que uma empresa A seja relativamente eficiente é que sua operação (avaliação) seja 'melhor' que as demais consideradas se A tiver o poder de definir os 'preços' ('pesos')”.

A Análise por Envoltória de Dados pode ser considerada, portanto, como um corpo de conceitos e metodologias que está incorporada a uma coleção de modelos, com possibilidades interpretativas diversas (CHARNES, COOPER, LEWIN \& SEIFORD, 1997, p. 23). Entre esses modelos os mais largamente utilizados são:

- Modelo CCR (1978) - desenvolvido por Charnes, Cooper e Rhodes, permite uma avaliação objetiva da eficiência global e identifica as fontes e estimativas de montantes das ineficiências identificadas.

- Modelo BCC (1984) - criado por Banker, Charnes e Cooper, distingue entre ineficiências técnicas e de escala, estimando a eficiência técnica pura, a uma dada escala de operações, e identificando se estão presentes ganhos de escala crescentes, decrescentes e constantes, para futura exploração.

Segundo PAIVA (2000, p. 42),

as diferenças fundamentais entre os modelos estão relacionadas a:

$>$ superfície de envelopamento (tipos de combinação e suposições sobre o retorno de escala); e

$>$ tipo de projeção do plano ineficiente à fronteira.

Os modelos CCR e BCC trabalham com diferentes tipos de tecnologias e, conseqüentemente geram fronteiras de eficiência diferentes e medidas de eficiência diferentes. No que diz respeito à orientação, cada um desses dois modelos pode ser escrito sob duas formas de projetar os planos ineficientes na fronteira: uma voltada para os produtos e outra voltada para os insumos. Na primeira orientação, as projeções dos planos observados sobre a fronteira buscam o máximo aumento equiproporcional de produção dado o consumo observado e, na segunda orientação, a maior redução equiproporcional do consumo para a produção observada.

Será apresentada e discutida a formulação matemática de cada modelo, com as possibilidades de orientação já expostas. A preocupação na apresentação dos modelos será aprofundar suas características, limitações e possibilidades, de forma a estender sua compreensão a não-especialistas. 
A formulação original do Modelo CCR tem orientação ao consumo e foi apresentada no item anterior. Está reproduzida a seguir para discussão:

$$
\begin{aligned}
& \text { Maximizar }_{k}=\sum_{r=1}^{s} u_{r} y_{r k}, \\
& \text { sujeito a } \\
& \sum_{r=1}^{m} u_{r} y_{r j}-\sum_{i=1}^{n} v_{i} x_{i j} \leq 0 \\
& \sum_{i=1}^{n} v_{i} x_{i k}=1 \\
& u_{r}, v_{i} \geq 0 \\
& y_{r}=\text { quantidade de produto } r ; x_{i}=\text { quantidade de insumo } i ; \\
& u, v=\text { pesos } \\
& r=1, \ldots, m ; i=1, \ldots, n ; j=1, \ldots, N
\end{aligned}
$$

O modelo busca minimizar os consumos de insumos de forma a produzir no mínimo o nível de produção dado, expresso pela maximização do somatório das quantidades produzidas y multiplicadas pelos pesos $u$.

A primeira restrição (eq. 3.6) pode ser definida como o resultado da empresa, pois é a subtração entre o somatório das quantidades produzidas multiplicadas pelos pesos dos produtos $\left(\sum_{r=1}^{m} u_{r} y_{r j}\right)$ e o somatório da multiplicação dos insumos consumidos pelos pesos $\left(\sum_{i=1}^{n} v_{i} x_{i j}\right)$. Está limitado a 0 . Assim, as empresas eficientes obterão o resultado 0 para a primeira restrição.

Na segunda restrição (eq. 3.7), o somatório do produto das quantidades consumidas de recursos pelos pesos específicos para a empresa $k\left(\sum_{i=1}^{n} v_{i} x_{i k}\right)$ é igual a 1 . Portanto, o máximo resultado possível de se obter para $h_{k}$ é 1 . Se a empresa $k$ for eficiente, $h_{k}$ será igual a 1. Se não for, obterá um indicador sempre inferior a 1. Após resolver o programa linear para cada uma das empresas, obtém-se o grupo de empresas eficientes, para as quais $h_{k}$ é igual a 1. O Modelo CCR pode ter orientação a produto com a seguinte formulação:

Minimizar $h_{k}=\sum_{i=1}^{n} v_{i} x_{i k}$,

sujeito a

$\sum_{r=1}^{m} u_{r} y_{r j}-\sum_{i=1}^{n} v_{i} x_{i j} \leq 0$

$\sum_{r=1}^{m} u_{r} y_{r k}=1$

$u_{r}, v_{i} \geq 0$

$y_{r}=$ quantidade de produto $r ; x_{i}=$ quantidade de insumo $i$; 


$$
\begin{aligned}
& u, v=\text { pesos } \\
& r=1, \ldots, m ; \quad i=1, \ldots, n ; j=1, \ldots, N
\end{aligned}
$$

O objetivo é a maximização do nível de produção utilizando no máximo o consumo de insumos observados. Os modelos são equivalentes e pressupõem retornos constantes de escala.

O outro Modelo de DEA é chamado de BCC, abreviatura de Banker, Charnes e Cooper, que o desenvolveram e apresentaram em artigo publicado na Management Science em 1984. O Modelo BCC pressupõe que as unidades avaliadas apresentem retornos variáveis de escala. Segundo BELLONI (2000, p. 68) "ao possibilitar que a tecnologia exiba propriedades de retornos à escala diferentes ao longo de sua fronteira, esse modelo admite que a produtividade máxima varie em função da escala de produção". A formulação matemática do Modelo BCC, com orientação ao consumo, é:

$$
\begin{aligned}
& \text { Maximizar } \sum_{r=1}^{m} u_{r} y_{r k}-u_{k}, \\
& \text { sujeito a } \\
& \sum_{i=1}^{n} v_{i} x_{i k}=1 \\
& \sum_{r=1}^{m} u_{r} y_{r j}-\sum_{i=1}^{n} v_{i} x_{i j}-u_{k} \leq 0 \\
& u_{r}, v_{i} \geq 0 \\
& y_{r}=\text { quantidadede produto } r ; x_{i}=\text { quantidade de insumo } i ; \\
& u, v=\text { pesos } \\
& r=1, \ldots, m ; i=1, \ldots, n ; j=1, \ldots, N
\end{aligned}
$$

Percebe-se que é introduzida uma variável $u_{k}$ representando os retornos variáveis de escala. Essa variável não deve atender à restrição de positividade; pode, portanto, assumir valores negativos. A formulação matemática do Modelo BCC, com orientação ao produto, é:

Minimizar $\sum_{i=1}^{n} v_{i} x_{k i}+v_{k}$,

sujeito a

$\sum_{r=1}^{m} u_{r} y_{r k}=1$

$\sum_{r=1}^{m} u_{r} y_{j r}-\sum_{i=1}^{n} v_{i} x_{j i}-v_{k} \leq 0$

$u_{r}, v_{i} \geq 0$

$y_{r}=$ quantidade de produto $r ; x_{i}=$ quantidade de insumo $i$;

$u, v=$ pesos

$r=1, \ldots, m ; i=1, \ldots, n ; j=1, \ldots, N$ 
Onde, novamente, o termo $v_{k}$ representa a possibilidade de retornos de escala variáveis, podendo assumir valores negativos ou positivos.

Como ressaltado anteriormente, a possibilidade de retornos de escala variáveis do Modelo BCC admite que a produtividade máxima varie em função da escala de produção. 0 modelo permite, portanto, a utilização de unidades de portes distintos (BELLONI, 2000, p. 68).

Os Modelos CCR e BCC apresentam regiões de viabilidade distintas. A região viável do Modelo BCC é restringida a combinações convexas dos planos de produção observados, o que é caracterizado pelos retornos variáveis de escala. Como conseqüência, considerando orientação ao produto, o indicador de eficiência do Modelo BCC é menor ou igual ao indicador de eficiência do Modelo CCR (BELLONI, 2000, p 69). Os indicadores calculados pelos modelos podem ser analisados considerando as seguintes características:

- Indicador de eficiência do Modelo BCC: corresponde a uma medida de eficiência técnica (ET), uma vez que está depurado dos efeitos de escala de produção.

- Indicador de eficiência do Modelo CCR: indica uma medida de produtividade global, denominada de indicador de eficiência produtiva (EP).

Relacionando os indicadores, calculados considerando-se orientação ao produto, obtém-se o indicador de eficiência de escala (EEs):

$$
\begin{aligned}
& \operatorname{EEs}\left(x_{k}, y_{k}\right)=\frac{E P\left(x_{k}, y_{k}\right)}{\operatorname{ET}\left(x_{k}, y_{k}\right)}, \\
& \text { Onde } \\
& \text { EEs }\left(x_{k}, y_{k}\right)=\text { Eficiência de escala, } \\
& \operatorname{EP}\left(x_{k}, y_{k}\right)=\text { Eficiência produtiva, } \\
& \operatorname{ET}\left(x_{k}, y_{k}\right)=\text { Eficiência técnica }
\end{aligned}
$$

As análises possíveis são assim resumidas:

- Se o indicador de eficiência produtiva (EP) for igual a 1, a unidade opera com eficiência produtiva e deve ter os demais indicadores (EE, ET) iguais a 1.

- Se o indicador de eficiência produtiva (EP) for superior a 1, a unidade analisada apresenta ineficiência produtiva, que pode ser decorrente de ineficiência técnica $(\mathrm{ET})$ ou de escala $(\mathrm{EE})$.

- Se o indicador de eficiência técnica (ET) for igual a 1, a ineficiência produtiva é decorrente de a unidade operar em uma escala inapropriada.

- Se o indicador de eficiência técnica (ET) for maior que 1, a unidade opera com ineficiência técnica. Calcula-se, então, o indicador de eficiência de escala (EE) para constatar se a unidade opera com eficiência de escala.

- Se o indicador de eficiência de escala (EE) for igual a 1, toda a ineficiência é decorrente de fatores técnicos.

- Se o indicador de eficiência de escala (EE) for maior que 1, a unidade analisada apresenta fatores de ineficiências técnicas e de escala.

Para finalizar, a Figura 2 resume os modelos DEA e suas aplicações, apresentando uma indicação para sua utilização. 


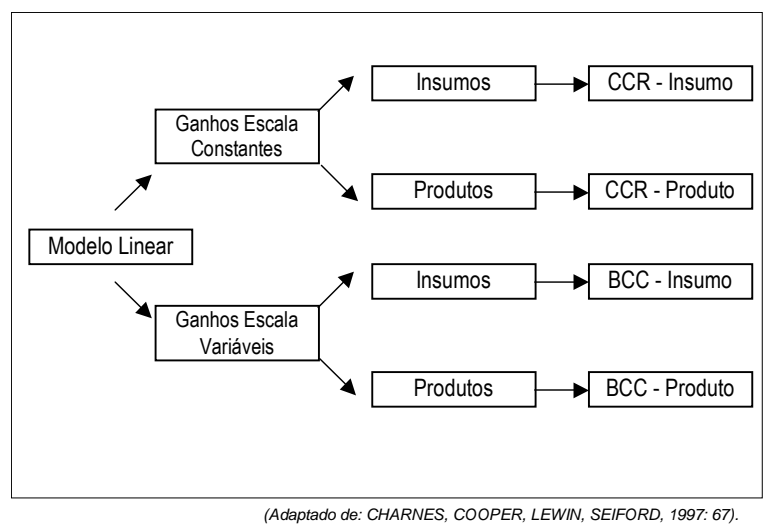

Figura 2 - Classificação entre ganhos de escala e orientação

\section{OUTRAS POSSIBILIDADES DE APLICAÇÃO DE DEA À CONTABILIDADE}

A literatura sobre DEA é bastante extensa. Charnes, Cooper, Lewin e Seiford (1997, p. 11) citam que no período de 1978 a 1992 mais de 400 artigos, livros e dissertações envolvendo DEA foram publicados no exterior. Considerando-se a Base Proquest em CDROM, que contém mais de 1.000 periódicos de língua inglesa nas áreas de administração, marketing e negócios, uma pesquisa cobrindo o período de janeiro de 1986 a junho de 2002, revela mais de 653 artigos publicados sobre DEA. No entanto, a literatura relacionando DEA especificamente à Contabilidade não é tão profícua.

No exterior, estudos utilizam dados contábeis para análise do desempenho de empresas com base em dados contábeis (ZHU, 2000; SMITH, 1990; FERNANDEZ-CASTRO \& SMITH, 1994). O setor bancário é um dos mais constantes objetos de análise de eficiência com utilização de DEA, abrangendo tanto avaliação externa como interna das instituições (BERGER \& HUMPHREY, 1997). Estudos utilizaram DEA e informações contábeis para previsão de insolvência (SIMAK, 1997; SIMAK, 2000). No Brasil, estudos começam a aparecer utilizando informações contábeis e DEA para avaliação da performance das empresas (CERETTA \& NIEDERAUER, 2000; SILVA, 2000; CASA NOVA, 2002).

No item 5 , a seguir, será apresentado um exemplo prático utilizando informações de empresas do setor elétrico brasileiro. 0 exemplo tem finalidades didáticas e o objetivo de, tão-somente, explorar as possibilidades da aplicação da Análise por Envoltória de Dados às informações contábeis.

\section{APRESENTAÇÃO DE UM EXEMPLO PRÁTICO}

Para o exemplo serão utilizados dados de um conjunto de empresas brasileiras do setor de energia elétrica. Para facilitar a simulação, o modelo será desenvolvido utilizando a ferramenta Solver $®$ do Excel $®$. Ressalte-se, ainda, que o exemplo atende somente a finalidades didáticas, não se considerando válidas as análises depuradas das relações que estabelece ou, em outras palavras, o objetivo não é entrar no mérito dos resultados apurados, mas, demonstrar a aplicação dos pressupostos do DEA como uma ferramenta quantitativa para avaliação da performance das empresas. 
Foram incluídas sete empresas para a preparação do exemplo, para as quais se relacionaram o número de funcionários, valor total de vendas e o ativo total. Os dados estão reproduzidos na Tabela 1.

Tabela 1 - Empresas consideradas no exemplo

\begin{tabular}{|c|c|c|c|}
\hline Empresas & $\begin{array}{l}\text { Número de } \\
\text { Empregados }\end{array}$ & Ativo & Vendas \\
\hline Celesc & 4.478 & $\begin{array}{c}1.487 .84 \\
5\end{array}$ & 800.331 \\
\hline Coelba & 3.320 & $\begin{array}{c}1.599 .78 \\
4\end{array}$ & 780.880 \\
\hline CPFL & 4.176 & $\begin{array}{c}3.888 .61 \\
3\end{array}$ & $\begin{array}{c}1.582 .62 \\
4\end{array}$ \\
\hline Light & 5.988 & $\begin{array}{c}5.147 .80 \\
7\end{array}$ & $\begin{array}{c}1.977 .70 \\
4\end{array}$ \\
\hline Eletropaulo & 6.646 & $\begin{array}{c}5.221 .84 \\
7 \\
\end{array}$ & $\begin{array}{c}3.105 .86 \\
9 \\
\end{array}$ \\
\hline Copel & 6.536 & $\begin{array}{c}5.299 .04 \\
9\end{array}$ & $\begin{array}{c}1.305 .44 \\
4\end{array}$ \\
\hline Cemig & 11.748 & $\begin{array}{c}7.475 .83 \\
1\end{array}$ & $\begin{array}{c}2.349 .30 \\
6\end{array}$ \\
\hline
\end{tabular}

Pela análise da Tabela 1 constata-se que as empresas têm número de funcionários e volume de vendas variáveis. A empresa com o maior número de funcionários é a Cemig, com 11.748 colaboradores. Mas, contrariamente ao que se poderia esperar, não é a Cemig que apresenta o maior valor de vendas. A Eletropaulo, com 6.646 colaboradores, obteve US\$ 3.105.869 de vendas. A Figura 3 mostra a posição de vendas em relação ao número de funcionários de cada empresa considerada.

Figura 3 - Vendas em relação ao número de funcionários - empresas do exemplo

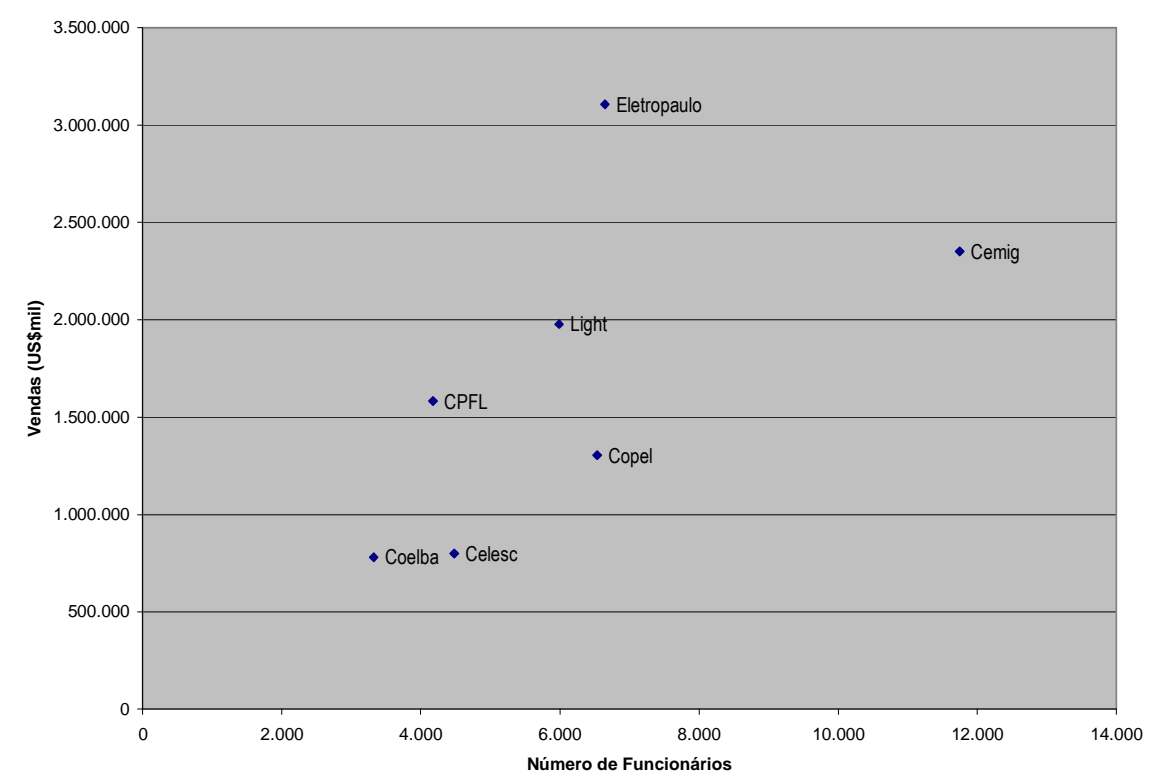


Com relação a Ativo e Vendas, as análises se repetem: a empresa com maior Ativo, Cemig, não é a que tem o maior volume de vendas. Novamente, a atuação da Eletropaulo supera as demais empresas. Outro fato interessante é que a Celesc, que tem o menor montante de Ativo, supera em vendas a penúltima colocada Coelba. As análises estão representadas na Figura 4.

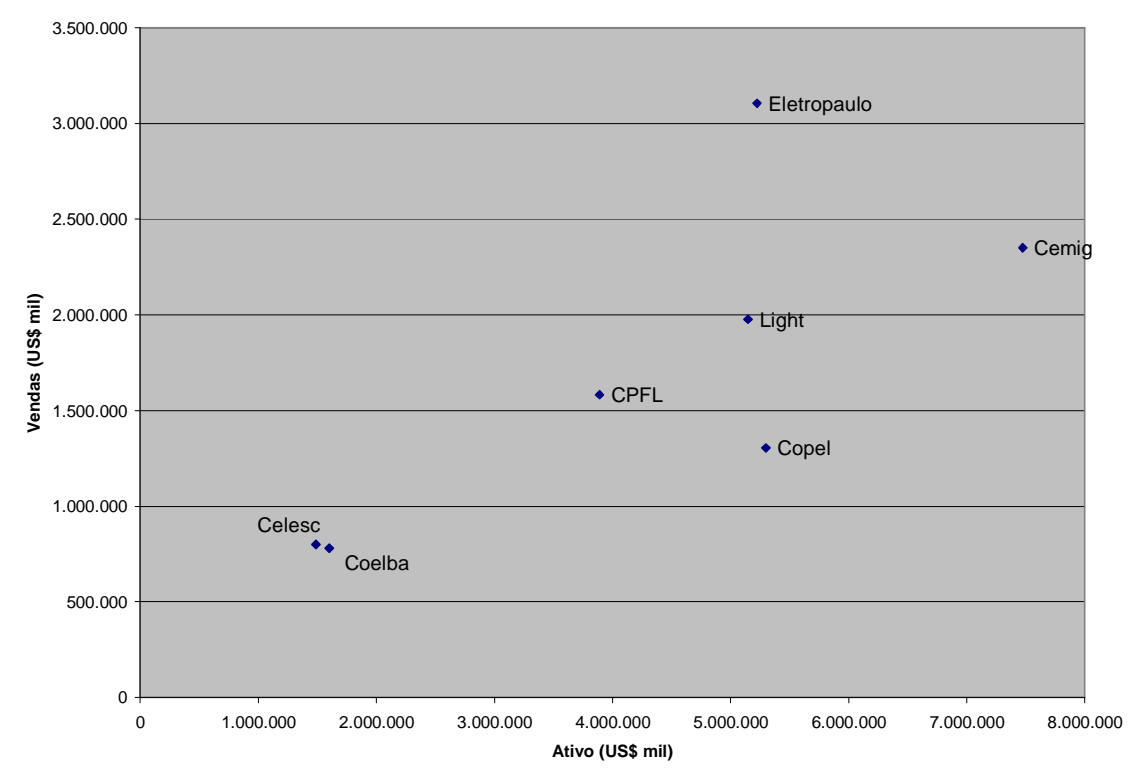

Figura 4 - Ativo em relação a vendas - empresas do exemplo

Cabe a pergunta: Coelba, Copel, Light, CPFL e Celesc, com base nas informações apresentadas, podem ser consideradas eficientes em sua operação?

Para se responder à pergunta poder-se-ia pensar em uma medida ponderada entre vendas e número de funcionários: um indicador. Para as empresas analisadas, os indicadores vendas por funcionário e vendas por ativo são apresentados na Tabela 2.

Tabela 2 - Indicadores para as empresas do exemplo

\begin{tabular}{l|l|l|} 
Empresas & $\begin{array}{l}\text { Vendas / } \\
\text { Funcionários }\end{array}$ & $\begin{array}{l}\text { Vendas/ } \\
\text { Ativo }\end{array}$ \\
\hline Eletropaulo & 467,33 & 0,59 \\
\hline CPFL & 378,98 & 0,41 \\
\hline Light & 330,28 & 0,38 \\
\hline Coelba & 235,20 & 0,49 \\
\hline Cemig & 199,97 & 0,31 \\
\hline Copel & 199,73 & 0,25 \\
\hline Celesc & 178,73 & 0,54
\end{tabular}

A análise dos indicadores indica novamente a superioridade da operação da Eletropaulo, sendo seguida por CPFL. Celesc apresenta o menor indicador de vendas por funcionários para as empresas analisadas. Porém, é a segunda colocada se considerado o giro $(0,54)$, perdendo apenas para a Eletropaulo. Deveria ser considerada ineficiente ou eficiente? 
A Figura 5 resume as informações. A Eletropaulo aparece graficamente posicionada muito distante das demais empresas, podendo ser classificada como outlier. Nas análises estatísticas tradicionais, seria estudada a conveniência de sua exclusão, pois seu comportamento mostra-se muito distinto das outras unidades em observação. $\mathrm{Na}$ análise DEA, seu comportamento será utilizado para compreender e avaliar a atuação das demais unidades, com a indicação de alternativas às demais para alcançar um desempenho semelhante, em sua escala de operação.

Figura 5 - Indicadores para as empresas do exemplo

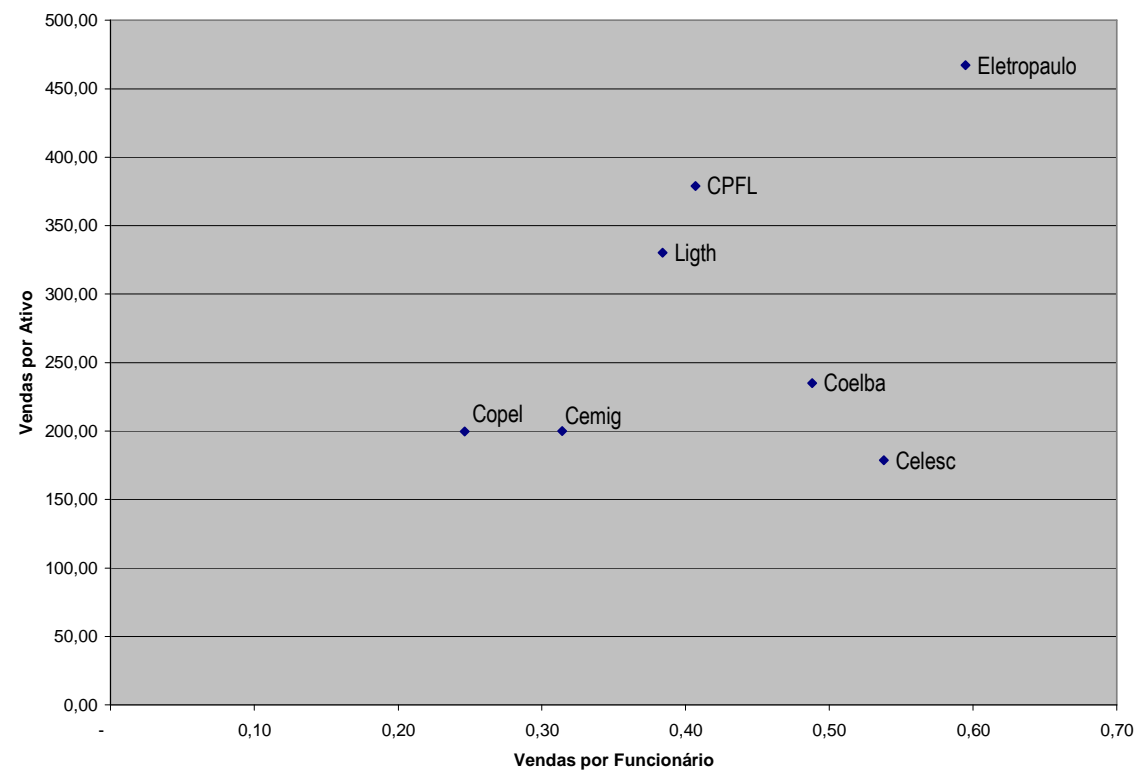

Construiu-se, então, um modelo DEA para avaliação do grupo de empresas. 0 modelo considera retornos constantes de escala e orientação ao insumo: é o CCR orientado ao insumo, apresentado nas Equações 3.5 a 3.8.

É montada, inicialmente, uma planilha com as informações apresentadas. Para o modelo, o número de funcionários e o montante de ativos são considerados insumos e o valor de vendas, produto. Para cada empresa é, então, calculada uma equação que relaciona o valor de vendas multiplicado por um peso $u$, subtraído da soma do número de funcionários multiplicado pelo peso $v 1 \mathrm{com}$ o montante de ativos multiplicado por v2. Para tanto, determinam-se as células que contêm os valores de $u, v 1$ e $v 2$. É escolhida, ainda, uma célula para conter o valor a ser maximizado, que é o produto entre o valor de vendas e o respectivo peso da empresa sendo analisada $\left(h_{k}\right)$, e outra para conter a restrição de que a soma dos valores dos insumos pelos respectivos pesos seja igual a 1 (Insumos).

A Figura 6 apresenta as opções a serem preenchidas para elaboração do Modelo. A primeira definição é da célula de destino e da condição a ser atendida: Máx (Maximizar), Mín (Minimizar) ou Valor de. No exemplo, a célula de destino é B14.

As células variáveis são as dos pesos $u, v 1$ e v2: C14, D14 e E14. Os pesos são estimados pelo Modelo. Finalmente, serão incluídas as restrições. De acordo com as Equações de 2.6 a 2.8, as restrições são: de que os pesos $u, v 1$ e $v 2$ sejam maiores do que 0 ; de que a equação, para cada empresa, seja menor ou igual a 0 ; e, de que a multiplicação dos pesos pela quantidade de insumos da empresa analisada seja igual a 1.

Seleciona-se, então, o botão Opções e, na janela que se abre, deve ser marcado Presumir Modelo Linear. Com os parâmetros definidos é preciso somente acionar o botão Resolver na caixa de diálogo, do Solver $®$, ferramenta do Excel $\circledast$. 
Figura 6 - Parâmetros do Solver ${ }^{\circledR}$ para Modelo DEA

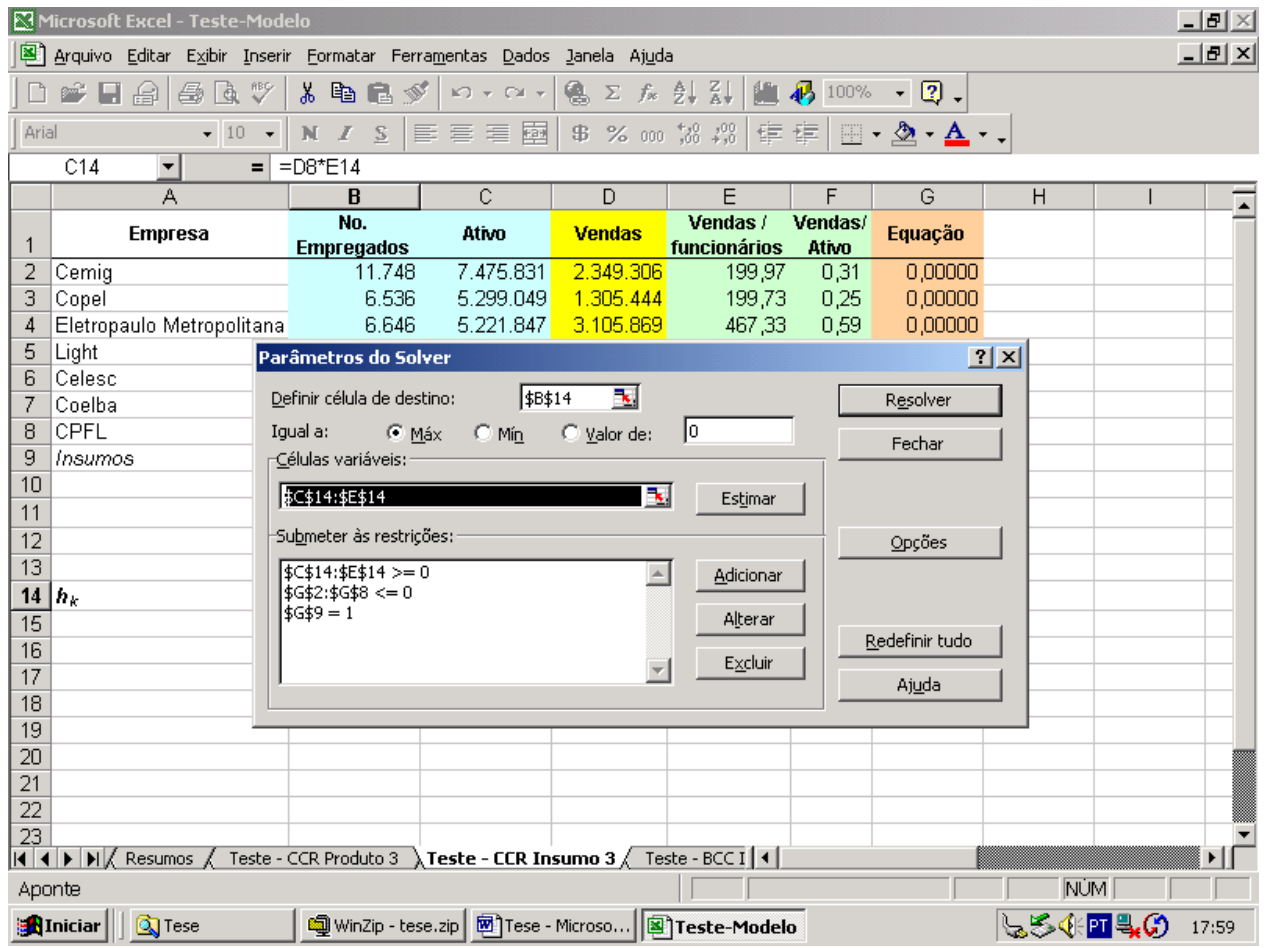

O modelo deve ser resolvido para cada empresa, modificando as fórmulas das células B14 $\left(h_{k}\right)$ e E9 (Insumos), para que contemplem as quantidades da empresa sob análise.

A Figura 7 mostra os resultados do Solver ${ }^{\circledR}$ para essa empresa. A conclusão é de que a operação da Cemig não é eficiente $\left(h_{k}=0,5283493<1\right)$. E, pela análise da coluna Equação, conclui-se que Eletropaulo Metropolitana é eficiente, considerando os pesos definidos pela operação da Cemig: o resultado da Equação para a empresa é 0. 
Figura 7 - Solução para a Cemig

\begin{tabular}{|c|c|c|c|c|c|c|c|c|c|c|}
\hline $\mathbb{M}$ & licrosoft Excel - Teste-Mode & & & & & & & & & - $|x| x \mid$ \\
\hline 图 & Árquivo Editar Exibir Inserir & $r$ Formatar Fer & erramentas Dados & leanela Ajüda & & & & & & - \\
\hline$\rfloor$ & 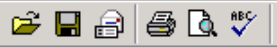 & 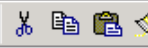 & $\theta|n+\infty=|$ & $\sum \Sigma f_{x}$ & $\mathrm{~A} \downarrow \mathbf{Z} \downarrow \mathbf{A} \downarrow$ & 解 $100 \%$ & - ?. & & & \\
\hline Aria & $\begin{array}{rr}-9 & -1\end{array}$ & $\mathbf{N} \quad \boldsymbol{I} \quad \underline{\mathbf{S}}$ & 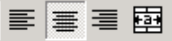 & 中 \% 000 & 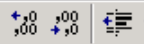 & 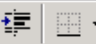 & A. & & & \\
\hline & $\nabla=E$ & Empresa & & & & & & & & \\
\hline & A & $B$ & C & D & $E$ & $\mathrm{~F}$ & G & $\mathrm{H}$ & 1 & $\overline{1}$ \\
\hline 1 & Empresa & $\begin{array}{c}\text { No. } \\
\text { Empregados }\end{array}$ & Ativo & Vendas & $\begin{array}{c}\text { Vendas / } \\
\text { funcionários }\end{array}$ & $\begin{array}{c}\text { Vendas! } \\
\text { Ativo }\end{array}$ & Equação & & & \\
\hline 2 & Cemig & 11.748 & 7.475 .831 & 2.349 .306 & 199,97 & 0,31 & $-0,47165$ & & & \\
\hline 3 & Copel & 6.536 & 5.299 .049 & 1.305 .444 & 199,73 & 0,25 & $-0,41524$ & & & \\
\hline 4 & Eletropaulo Metropolitana & 6.646 & 5.221 .847 & 3.105 .869 & 467,33 & 0,59 & 0,00000 & & & \\
\hline 5 & Light & 5.988 & 5.147 .807 & 1.977 .704 & 330,28 & 0,38 & $-0,24382$ & & & \\
\hline 6 & Celesc & 4.478 & 1.487 .845 & 800.331 & 178,73 & 0,54 & $-0,01903$ & & & \\
\hline 7 & Coelba & 3.320 & 1.599 .784 & 780.880 & 235,20 & 0,49 & $-0,03838$ & & & \\
\hline 8 & CPFL & 4.176 & 3.888 .613 & 1.582 .624 & 378,98 & 0,41 & $-0,16423$ & & & \\
\hline 9 & insumos & & & & & & 1,00000 & & & \\
\hline 10 & & & & & & & & & & \\
\hline 11 & & & & & & & & & & \\
\hline 12 & & & & & & & & & & \\
\hline 13 & & & $v 1$ & $v 2$ & $u$ & & & & & \\
\hline 14 & $\boldsymbol{h}_{k}$ & 0,5283493 & 0,0000000 & 0,0000001 & 0,0000002 & & & & & \\
\hline 15 & & & & & & & & & & \\
\hline 16 & & & & & & & & & & \\
\hline 17 & & & & & & & & & & \\
\hline 18 & & CCRMax & & & & & & & & \\
\hline 19 & & & & & & & & & & \\
\hline 20 & & & & & & & & & & \\
\hline 21 & & & & & & & & & & \\
\hline 22 & & & & & & & & & & \\
\hline 23 & & & & & & & & & & \\
\hline 24 & & & & & & & & & & $\nabla$ \\
\hline \begin{tabular}{|l|l}
14 & 1 \\
\end{tabular} & - M/Resumos / Teste - & CCR Produto 3 & $\lambda$ Teste - CCR Ins & umo 3 人 & 201 & & & & & -11 \\
\hline 因I & فㄱese & 고 WinZip - te & ese.zip 国Tese - & Microso... 图 & Teste-Modelo & & & & & $18: 01$ \\
\hline
\end{tabular}

Ao encontrar a solução, o Solver ${ }^{\circledR}$ apresenta uma caixa de diálogo Resultados do Solver. Para ter-se acesso às sugestões de melhoria, caso a empresa não seja eficiente, deve ser solicitado o Relatório de Sensibilidade. A Figura 8 mostra o Relatório de Sensibilidade gerado para a Cemig.

O relatório apresenta o preço sombra para as restrições, que são as equações de cada empresa e dos insumos, no Modelo CCR - Orientação ao Consumo. Já havia sido indicado pela solução que somente a Eletropaulo conseguiu ser eficiente com a melhor combinação de pesos para a Cemig. A Eletropaulo torna-se, então, referência para que a Cemig atinja a fronteira de eficiência. O Relatório de Sensibilidade, na coluna Sombra Preço, mostra o valor 0,75641 . Esse coeficiente, aplicado aos insumos e produtos da Eletropaulo, fornece as metas de melhoria para a Cemig. 
Figura 8 - Relatório de Sensibilidade - Cemig

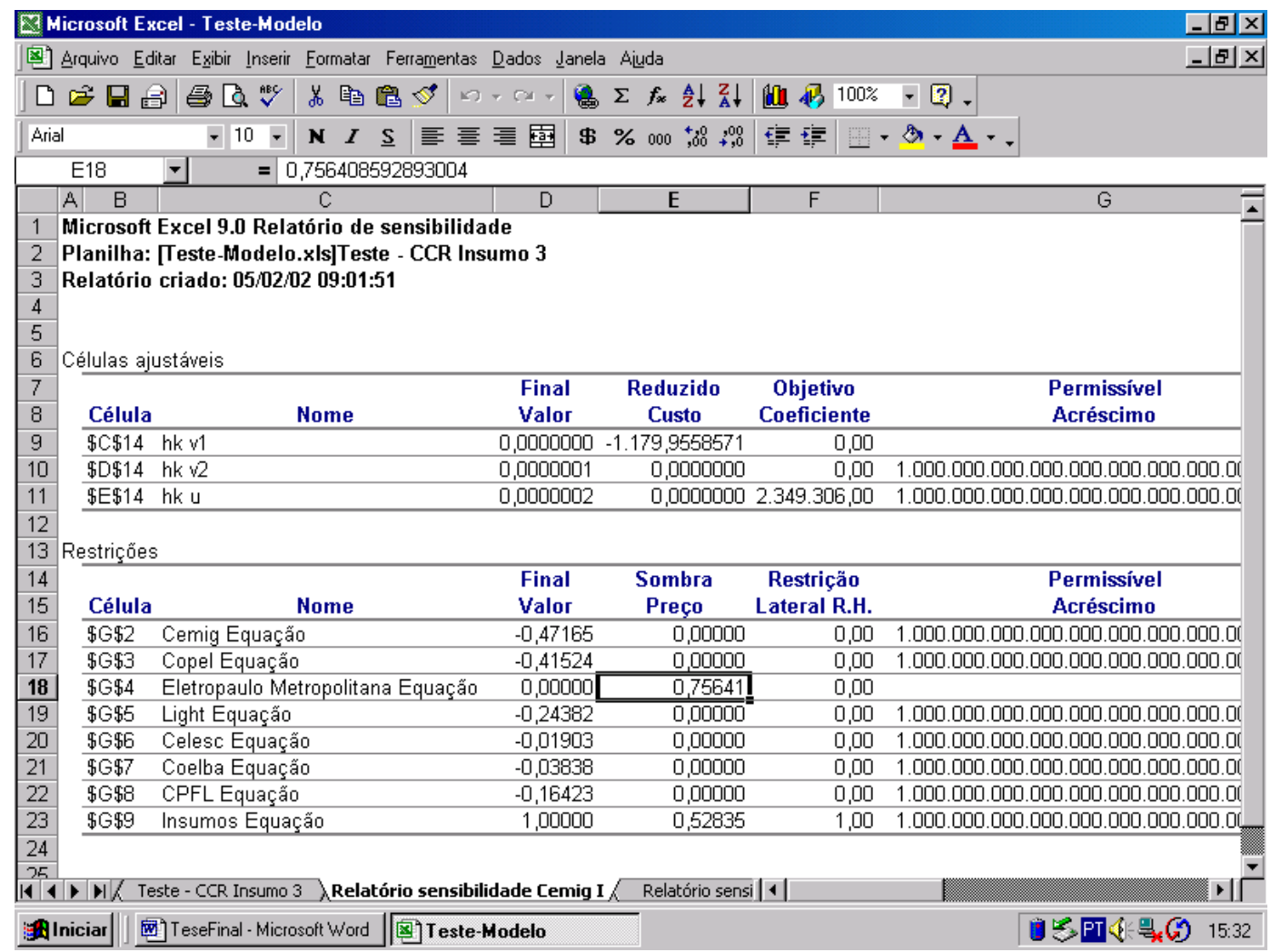

A Tabela 3 resume os cálculos. As sugestões referem-se a uma redução de $57,21 \%$ no número de empregados e de $47,17 \%$ nos investimentos em Ativos.

Tabela 3 - Metas para Cemig - CCR Insumo

\begin{tabular}{l|r|r|r|r|} 
Referência & Eletropaulo & Cemig & Diferença & $\%$ \\
\hline & 0,75641 & & & \\
\hline $\mathrm{N}^{\circ}$ Empregados & 5.027 & 11.748 & -6.721 & $-57,21 \%$ \\
\hline Ativo & 3.949 .850 & 7.475 .831 & -3.525 .981 & $-47,17 \%$ \\
\hline Vendas & 2.349 .306 & 2.349 .306 & 0 & $0 \%$ \\
\hline
\end{tabular}

O procedimento deve ser repetido para cada empresa analisada. Os resultados das simulações realizadas podem ser observados nas tabelas a seguir.

\section{Análise dos resultados}

$\mathrm{Na}$ Tabela 4 mostra-se que apenas uma das empresas do conjunto é eficiente: a Eletropaulo. Das demais empresas, apenas Light, Celesc, Coelba e CPFL aproximam-se da fronteira de eficiência com indicadores de eficiência de 0,706735, 0,904384, 0,820661 e 0,810951, respectivamente. 
Tabela 4 - Resultados do exemplo - Modelo CCR - Orientação ao consumo

\begin{tabular}{|l|l|l|l|l|l|l|l|} 
Empresa & \multicolumn{1}{l|}{} & Cemig & Copel & Eletropaulo Light & Celesc & Coelba & CPFL \\
\hline Cemig & $-0,471651$ & $-1,028291$ & $-0,675236$ & $-1,122396$ & $-2,369858$ & $-2,204036$ & $-1,609413$ \\
\hline Copel & $-0,415235$ & $-0,572611$ & $-0,594469$ & $-0,625014$ & $-2,086392$ & $-1,940404$ & $-0,896213$ \\
\hline Eletropaulo & 0,000000 & 0,000000 & 0,000000 & 0,000000 & 0,000000 & 0,000000 & 0,000000 \\
\hline Light & $-0,243816$ & $-0,268677$ & $-0,349058$ & $-0,293265$ & $-1,225078$ & $-1,139357$ & $-0,420515$ \\
\hline Celesc & $-0,019030$ & $-0,423108$ & $-0,027244$ & $-0,461830$ & $-0,095616$ & $-0,088925$ & $-0,662221$ \\
\hline Coelba & $-0,038377$ & $-0,252304$ & $-0,054943$ & $-0,275394$ & $-0,192831$ & $-0,179339$ & $-0,394889$ \\
\hline CPFL & $-0,164232$ & $-0,120788$ & $-0,235122$ & $-0,131842$ & $-0,825202$ & $-0,767462$ & $-0,189049$ \\
\hline$h_{k}$ & 0,528349 & 0,427389 & 1,000000 & 0,706735 & 0,904384 & 0,820661 & 0,810951 \\
\hline v1 & 0,000000 & 0,000153 & 0,000000 & 0,000167 & 0,000000 & 0,000000 & 0,000239 \\
\hline v2 & 0,000000 & 0,000000 & 0,000000 & 0,000000 & 0,000001 & 0,000001 & 0,000000 \\
\hline U & 0,000000 & 0,000000 & 0,000000 & 0,000000 & 0,000001 & 0,000001 & 0,000001 \\
\hline
\end{tabular}

O Modelo CCR com orientação ao produto pode ser implementado modificando-se: (1) a fórmula na célula B14, que passa a conter a multiplicação da quantidade de insumos consumidos pelos pesos (preços) específicos $v 1$ e $v 2 ;(2)$ a célula E9, que passa a registrar a multiplicação entre a quantidade de produtos pelo peso (preço) específico $u$; (3) o objetivo na caixa de Parâmetros do Solver, que é minimizar a célula B14. A Tabela 5 apresenta o resultado para o exemplo considerando o Modelo CCR com orientação ao produto.

Tabela 5 - Resultado do exemplo - Modelo CCR - Orientação ao produto

\begin{tabular}{|l|l|l|l|l|l|l|l|} 
Empresa & Cemig & Copel & \multicolumn{2}{|l}{ Eletropaulo Light } & Celesc & Coelba & CPFL \\
\hline Cemig & $-0,892687$ & $-2,405983$ & $-0,675236$ & $-1,588143$ & $-2,620410$ & $-2,685682$ & $-1,984600$ \\
\hline Copel & $-0,785910$ & $-1,339788$ & $-0,594469$ & $-0,884368$ & $-2,306975$ & $-2,364439$ & $-1,105139$ \\
\hline Eletropaulo & 0,000000 & 0,000000 & 0,000000 & 0,000000 & 0,000000 & 0,000000 & 0,000000 \\
\hline Light & $-0,461467$ & $-0,628646$ & $-0,349058$ & $-0,414957$ & $-1,354599$ & $-1,388340$ & $-0,518545$ \\
\hline Celesc & $-0,036017$ & $-0,989984$ & $-0,027244$ & $-0,653469$ & $-0,105725$ & $-0,108358$ & $-0,816599$ \\
\hline Coelba & $-0,072636$ & $-0,590337$ & $-0,054943$ & $-0,389670$ & $-0,213218$ & $-0,218529$ & $-0,486946$ \\
\hline CPFL & $-0,310840$ & $-0,282618$ & $-0,235122$ & $-0,186551$ & $-0,912447$ & $-0,935175$ & $-0,233121$ \\
\hline$h_{k}$ & 1,892687 & 2,339788 & 1,000000 & 1,414957 & 1,105725 & 1,218529 & 1,233121 \\
\hline v1 & 0,000000 & 0,000358 & 0,000000 & 0,000236 & 0,000000 & 0,000000 & 0,000295 \\
\hline v2 & 0,000000 & 0,000000 & 0,000000 & 0,000000 & 0,000001 & 0,000001 & 0,000000 \\
\hline $\mathrm{u}$ & 0,000000 & 0,000001 & 0,000000 & 0,000001 & 0,000001 & 0,000001 & 0,000001 \\
\hline
\end{tabular}

O Modelo CCR mostra resultados idênticos, com orientação ao consumo ou ao produto. Apenas a Eletropaulo é considerada relativamente eficiente, alcançando o indicador igual a 1. 0 indicador calculado no Modelo com orientação ao produto é o inverso do indicador apresentado na solução do Modelo com orientação ao insumo. Assim, para a Copel, $1 / 2,339788=0,427389$. As metas para as unidades ineficientes, no entanto, diferem. Para o caso da Cemig, as sugestões de melhoria estão resumidas na Tabela 6. 
Tabela 6 - Metas para Cemig - CCR Produto

\begin{tabular}{l|r|r|r|r|} 
Referência & Eletropaulo & Cemig & Diferença & $\%$ \\
\hline Preço-sombra & 1,43164 & & & \\
\hline$N^{\circ}$ Empregados & 9.515 & 11.748 & -2.233 & $-19,01 \%$ \\
\hline Ativo & 7.475 .831 & 7.475 .831 & 0 & $0,00 \%$ \\
\hline Vendas & 4.446 .502 & 2.349 .306 & 2.097 .196 & $89,27 \%$ \\
\hline
\end{tabular}

A indicação é de aumento de vendas de $89,27 \%$ e uma diminuição do número de funcionários de $19,01 \%$. A Eletropaulo, única empresa considerada eficiente, é novamente a referência na melhoria do desempenho da Cemig. A análise pode ser complementada com o desenvolvimento do Modelo BCC, que considera retornos variáveis à escala e permite segregar ineficiências de escala e técnica, conforme já discutido. Assim, são isolados efeitos decorrentes do porte das empresas.

Para o desenvolvimento do Modelo DEA - BCC com orientação ao consumo em Excel $\circledast$ parte-se das mesmas informações contidas na planilha anterior, acrescentando-se a variável $u_{k}$. A variável $u_{k}$ deverá ser subtraída da fórmula de $h_{k}$ e das equações de cada uma das empresas. As restrições não são modificadas. Novamente, o modelo deve ser resolvido para cada uma das empresas, modificando-se $h_{k}$ e Insumos, para que representem em suas fórmulas os valores da empresa em consideração. Os valores obtidos depois de resolvido o modelo para todas as empresas são apresentados na Tabela 7.

Tabela 7 - Resultado do exemplo - Modelo BCC - Orientação ao consumo

\begin{tabular}{|l|l|l|l|l|l|l|l|} 
Empresa & Cemig & Copel & \multicolumn{2}{|l}{ Eletropaulo Light } & Celesc & Coelba & CPFL \\
\hline Cemig & $-0,465406$ & $-1,033267$ & $-0,695074$ & $-0,961822$ & $-4,024603$ & $-2,538554$ & $-1,617202$ \\
\hline Copel & $-0,400375$ & $-0,406355$ & $-0,526941$ & $-0,440472$ & $-2,561560$ & $-0,968675$ & $-0,636000$ \\
\hline Eletropaulo & 0,000000 & $-0,129081$ & 0,000000 & 0,000000 & $-2,509671$ & $-1,001807$ & $-0,202029$ \\
\hline Light & $-0,234504$ & $-0,212696$ & $-0,297743$ & $-0,192093$ & $-2,459908$ & $-0,803614$ & $-0,332898$ \\
\hline Celesc & 0,000000 & $-0,173995$ & 0,000000 & $-0,146786$ & 0,000000 & $-0,348795$ & $-0,272326$ \\
\hline Coelba & $-0,019187$ & 0,000000 & 0,000000 & 0,000000 & $-0,075236$ & 0,000000 & 0,000000 \\
\hline CPFL & $-0,151660$ & 0,000000 & $-0,165589$ & 0,000000 & $-1,613587$ & $-0,257831$ & 0,000000 \\
\hline$h_{k}$ & 0,534594 & 0,593645 & 1,000000 & 0,807907 & 1,000000 & 1,000000 & 1,000000 \\
\hline v1 & 0,000000 & 0,000153 & 0,000021 & 0,000135 & 0,000000 & 0,000301 & 0,000239 \\
\hline v2 & 0,000000 & 0,000000 & 0,000000 & 0,000000 & 0,000001 & 0,000000 & 0,000000 \\
\hline$U$ & 0,000000 & 0,000000 & 0,000000 & 0,000000 & 0,000000 & 0,000000 & 0,000000 \\
\hline Vk & $-0,025635$ & $-0,380397$ & $-0,109027$ & $-0,310992$ & $-1,000000$ & $-1,000000$ & $-0,595373$ \\
\hline
\end{tabular}

Conforme já discutido, a empresa classificada como eficiente pelo Modelo CCR, Eletropaulo, é também considerada eficiente pelo Modelo BCC. Conclui-se que a Eletropaulo opera com eficiência produtiva, técnica e de escala. Aparecem ainda classificadas como eficientes Celesc, Coelba e CPFL, consideradas ineficientes no Modelo CCR. As metas para as empresas ineficientes podem ser calculadas considerando os preçossombra do Relatório de Sensibilidade, a serem gerados na solução de cada empresa. No caso da Cemig, as sugestões de melhoria são mostradas na Tabela 8. 
Tabela 8 - Metas para Cemig - Modelo BCC Insumo

\begin{tabular}{|l|r|r|r|r|r|r|} 
Referência & Eletropaulo & Celesc & Meta & Cemig & Diferença $\%$ \\
\hline Preço-Sombra & 0,67185 & 0,32815 & 1 & & & \\
\hline $\mathrm{N}^{\circ}$ Empregados & 4.465 & 1.469 & 5.935 & 11.748 & -5.813 & $-49,48 \%$ \\
\hline Ativo & 3.508 .296 & 488.237 & 3.996 .533 & 7.475 .831 & -3.479 .298 & $-46,54 \%$ \\
\hline Vendas & 2.086 .677 & 262.629 & 2.349 .306 & 2.349 .306 & 0 & $0,00 \%$ \\
\hline
\end{tabular}

Para discriminar ineficiência técnica e de escala, foram calculados os indicadores de eficiência segundo o Modelo BCC com orientação ao produto. Para tanto, foram efetuadas as seguintes alterações: (1) é acrescentada a variável $v_{k}$; $(2)$ a célula B14 passa a conter a multiplicação das quantidades consumidas pelo peso específico $v$, somada à variável $v_{k}$; (2) a célula E9 apresenta a multiplicação do volume de produção pelo peso específico $u$; (4) a variável $v_{k}$ é subtraída da equação de cada empresa. Os resultados estão resumidos na Tabela 9.

Tabela 9 - Resultados do exemplo - Modelo BCC - Orientação ao produto

\begin{tabular}{|l|l|l|l|l|l|l|l|} 
Empresa & Cemig & Copel & Eletropaulo Light & Celesc & Coelba & CPFL \\
\hline Cemig & $-0,322037$ & $-2,989755$ & $-0,691682$ & $-1,973479$ & $-2,684230$ & $-3,102881$ & $-2,466131$ \\
\hline Copel & $-0,766365$ & $-1,327202$ & $-0,595032$ & $-0,876060$ & $-2,309161$ & $-2,352322$ & $-1,094757$ \\
\hline Eletropaulo & 0,000000 & 0,000000 & 0,000000 & 0,000000 & 0,000000 & 0,000000 & 0,000000 \\
\hline Light & $-0,480212$ & $-0,553358$ & $-0,348517$ & $-0,365261$ & $-1,352502$ & $-1,329156$ & $-0,456443$ \\
\hline Celesc & $-0,981370$ & $-0,741921$ & 0,000000 & $-0,489727$ & 0,000000 & 0,000000 & $-0,611981$ \\
\hline Coelba & $-0,989649$ & $-0,209776$ & $-0,028516$ & $-0,138469$ & $-0,110663$ & 0,000000 & $-0,173036$ \\
\hline CPFL & $-0,648381$ & 0,000000 & $-0,225395$ & 0,000000 & $-0,874697$ & $-0,739208$ & 0,000000 \\
\hline$h_{k}$ & 1,322037 & 2,327202 & 1,000000 & 1,365261 & 1,000000 & 1,000000 & 1,000000 \\
\hline v1 & 0,000000 & 0,000472 & 0,000000 & 0,000312 & 0,000000 & 0,000093 & 0,000390 \\
\hline v2 & 0,000000 & 0,000000 & 0,000000 & 0,000000 & 0,000001 & 0,000001 & 0,000000 \\
\hline$U$ & 0,000000 & 0,000001 & 0,000000 & 0,000001 & 0,000001 & 0,000001 & 0,000001 \\
\hline Vk & 1,322037 & $-0,760437$ & $-0,038099$ & $-0,501950$ & $-0,147852$ & $-0,486708$ & $-0,627255$ \\
\hline
\end{tabular}

Novamente, para obter-se o indicador de eficiência de 0 a 1 , é necessário calcularse o inverso do indicador apresentado na solução do Modelo com orientação ao produto. A Tabela 10 apresenta os indicadores de eficiência calculados pelo Modelo com orientação do produto, para cada um das empresas consideradas.

Tabela 10 - Indicadores de Eficiência - Modelo BCC - Orientação ao produto

\begin{tabular}{l|c|} 
Empresa & Indicador \\
\hline Cemig & 0,7564 \\
\hline Copel & 0,4297 \\
\hline Eletropaulo & 1,0000 \\
\hline Light & 0,7325 \\
\hline Celesc & 1,0000 \\
\hline Coelba & 1,0000 \\
\hline CPFL & 1,0000 \\
\hline
\end{tabular}


Os indicadores dos Modelos BCC com orientação ao produto e ao insumo não são iguais, como acontece com o Modelo CCR, mas mantêm a classificação entre empresas eficientes e ineficientes. A comparação dos indicadores obtidos com cada orientação é resumida na Tabela 11.

Tabela 11 - Comparação dos indicadores do Modelo BCC

\begin{tabular}{l|r|r|} 
Empresa & Or. Insumo & Or. Produto \\
\hline Cemig & 0,5346 & 0,7564 \\
\hline Copel & 0,5936 & 0,4297 \\
\hline Eletropaulo & 1,0000 & 1,0000 \\
\hline Light & 0,8079 & 0,7325 \\
\hline Celesc & 1,0000 & 1,0000 \\
\hline Coelba & 1,0000 & 1,0000 \\
\hline CPFL & 1,0000 & 1,0000 \\
\hline
\end{tabular}

Igualmente diferem as sugestões de melhoria, considerando a orientação ao consumo. Para o caso da Cemig, as metas estão resumidas na Tabela 12.

Tabela 12 - Metas para Cemig - BCC Produto

\begin{tabular}{|l|r|r|r|r|} 
Referência & Eletropaulo & Cemig & Diferença & $\%$ \\
\hline Preço-Sombra & 1,00000 & & & \\
\hline$N^{\circ}$ Empregados & 6.646 & 11.748 & -5.102 & $-43,43 \%$ \\
\hline Ativo & 5.221 .847 & 7.475 .831 & -2.253 .984 & $-30,15 \%$ \\
\hline Vendas & 3.105 .869 & 2.349 .306 & 756.563 & $32,20 \%$
\end{tabular}

A unidade de referência é a Eletropaulo e as sugestões são de redução no número de funcionários e de investimentos nos ativos, de $43,43 \%$ e $30,15 \%$ respectivamente, e de aumento de $32,2 \%$ no volume de vendas.

Utilizando a Equação 2.21, pode-se calcular a eficiência de escala para cada uma das empresas, considerando os Modelos CCR e BCC com orientação ao produto. Os resultados são apresentados na Tabela 13.

Tabela 13 - Eficiência de escala

\begin{tabular}{l|r|r|r|} 
Empresa & $\begin{array}{r}\text { Eficiência } \\
\text { Produtiva }\end{array}$ & $\begin{array}{r}\text { Eficiência } \\
\text { Técnica }\end{array}$ & $\begin{array}{r}\text { Eficiência } \\
\text { de Escala }\end{array}$ \\
\hline Cemig & 1,8927 & 1,3220 & 1,4316 \\
\hline Copel & 2,3398 & 2,3272 & 1,0054 \\
\hline Eletropaulo & 1,0000 & 1,0000 & 1,0000 \\
\hline Light & 1,4150 & 1,3653 & 1,0364 \\
\hline Celesc & 1,1057 & 1,0000 & 1,1057 \\
\hline Coelba & 1,2185 & 1,0000 & 1,2185 \\
\hline CPFL & 1,2331 & 1,0000 & 1,2331 \\
\hline
\end{tabular}


Pela análise, Celesc, Coelba e CPFL apresentam ineficiências de escala, pois apresentam indicador de eficiência produtiva maior que 1 , indicador de eficiência técnica igual a 1 e indicador de escala maior que 1. Copel e Light, no entanto, apresentam ineficiência técnica. 0 indicador de eficiência produtiva foi maior que 1 , assim como o indicador de eficiência técnica. No entanto, o indicador de eficiência de escala é aproximadamente igual a 1. Conclusão: toda ineficência detectada é de natureza técnica. Para a Cemig, o Modelo identificou ineficiências de escala e técnica.

\section{CONSIDERAÇÕES FINAIS}

As simulações realizadas nesta pesquisa tiveram como finalidade demonstrar a adequação da aplicação do modelo DEA. No entanto, deve-se ressaltar um conjunto de restrições quanto ao uso da técnica e o nível de inferência dos resultados. Por exemplo, a principal ineficiência identificada nestas simulações é de natureza técnica. Destaca-se que, no caso da empresa Cemig, o modelo identificou, também, ineficiências de escala.

O modelo DEA permite uma análise multifacetada de eficiência: fatores críticos de sucesso, crescimento ou decrescimento, revisão de metas. Dentre as diversas possibilidades de aplicação da técnica de análise DEA, destaca-se, também, a avaliação de eficiência de empresas em fases pré e pós implementação; utilização para avaliação de custos de produção entre períodos; além de outras aplicações econômicas, financeiras e operacionais.

Ressaltem-se outras limitações: número de empresas consideradas e indicadores escolhidos. No tocante à limitação referente ao número de empresas, é necessário salientar que qualquer acréscimo ou exclusão modifica completamente o resultado da análise. O nível de eficiência obtido está condicionado, igualmente, aos indicadores selecionados.

Assim, o objetivo desse artigo foi abrir caminho para a expansão de pesquisas relacionando DEA e Contabilidade por meio da apresentação de um exemplo prático que, espera-se, simplifique sua utilização.

Em linhas gerais destacam-se as limitações no modelo DEA: é uma técnica ainda não explorada no âmbito contábil, e necessita de ambientação dos usuários para sua utilização; caracteriza-se como uma técnica não-paramétrica, não permitindo a extrapolação de suas conclusões, as quais estão restritas as empresas e as variáveis consideradas.

\section{REFERÊNCIAS}

ALTMAN, Edward L. Financial rates, discriminant analysis and the prediction of corporate bankruptcy. Journal of Finance, v. 23, 4, 1968.

ANDERSON, David R.; SWEENEY, Dennis J.; WILLIAMS, Thomas A. Estatística aplicada à Administração e Economia. São Paulo: Pioneira Thomson Learning, 2002.

BELLONI, José Ângelo. Uma metodologia de avaliação da eficiência produtiva de Universidade Federais Brasileiras. 2000. Tese (Doutorado em Engenharia de Produção) Programa de Pós-Graduação em Engenharia de Produção, do Departamento de Engenharia de Produção e Sistemas, da Universidade Federal de Santa Catarina. Florianápolis, 2000. 
BERGER, Allen N.; HUMPHREY, David B. Efficiency of financial institutions: international survey and directions for future research. European Journal of Operational Resarch, 98, p. 175-212, 1997.

BERNSTEIN, Peter L. O desafio aos deuses: a fascinante história do risco. Tradução de Ivo Korytowski. Rio de Janeiro: Campus, 1997.

BUSSAB, Wilton de O. \& MORETTIN, Pedro A. Estatística Básica. 5 ed. São Paulo: Saraiva, 2003.

CASA NOVA, Silvia Pereira de Castro. Utilização da Análise por Envoltória de Dados (DEA) na Análise de Demonstrações Contábeis. 1996. Tese (Doutorado em XXXXX) - Programa de Pós-Graduação em Controladoria e Contabilidade da Universidade de São Paulo. São Paulo, 1996.

CERETTA, Paulo Sergio; NIEDERAUER, Carlos A. P. Rentabilidade do setor bancário brasileiro. Encontro Nacional da ANPAD - Associação Nacional de Programas de PósGraduação em Administração, 24, 2000. Anais... Florianópolis, 10-13 set. 2000.

CHARNES, Abraham; COOPER, William W.; LEWIN, Arie Y.; SEIFORD, Lawrence M. Data Envelopment Analysis: theory, methodology, and application. Massachusetts: Kluwer, 1997.

EXAME. Os Melhores e os maiores - Brasil em Exame. Exame, São Paulo, set. 1974.

FERNANDEZ-CASTRO, A.; SMITH, P. Towards a general non-parametric model of corporate performance. Omega - International Journal of Management Science, 22, 3, p. 237-249, 1994.

HAIR, Joseph F. et alii. Multivariate data analysis. Englewood Cliffs: Prentice-Hall, 1998.

HUMES Jr., Carlos. Comunicação pessoal. São Paulo, 22 fev. 2001.

IUDíCIBUS, Sérgio de. Conhecimento, ciência, metodologias científicas e contabilidade. Revista Brasileira de Contabilidade, Brasília: Conselho Federal de Contabilidade, ano 26, 104, 1997.

KANITZ, Stephen C. Como Prever Falências. Exame, São Paulo: Abril, dez. 1974.

MARTINS, Eliseu. Que sorte: a contabilidade não é uma ciência exata. Temática Contábil e de Balanços. São Paulo: IOB - Informações Objetivas, Boletim nº 11, 1994.

MATARAZZO, Dante C. Análise Financeira de Balanços: abordagem básica e gerencial. 3 ed. São Paulo: Atlas, 1995.

PAIVA, Francisco Canindé de. Eficiência produtiva de programas de ensino de pósgraduação em engenharias: uma aplicação do método Análise Envoltória de Dados DEA. 2000. Dissertação (Mestrado em XXXXX) - Programa de Pós-Graduação em Engenharia de Produção, Universidade Federal de Santa Catarina. Florianópolis, 2000.

REIS, Solange Garcia dos. Ciência e contabilidade. Revista de Contabilidade do CRC - SP, São Paulo, ano I, 3, dez. 1997.

SILVA, Antônio Carlos Magalhães da. Análise da eficiência das instituições financeiras brasileiras, segundo a metodologia do Data Envelopment Analysis (DEA). 2000. Dissertação (Mestrado em XXXXXX) - Instituto de Pós-Graduação em Administração, Universidade Federal do Rio de Janeiro. Rio de Janeiro, 2000.

SIMAK, Paul C. DEA based analysis of corporate failure. 1997. Thesis (Masters of Applied Science) - Graduate Department of Mechanical and Industrial Engineering, University of Toronto. Toronto (Canadá): University of Toronto. 
SIMAK, Paul C. Inverse and Negative DEA and their application to credit risk evaluation. 2000. Thesis (Doctor of Philosophy) - Graduate Department of Mechanical and Industrial Engineering, University of Toronto. Toronto (Canadá): University of Toronto.

SMITH, P. Data Envelopment Analysis applied to financial statements. Omega International Journal of Management Science, 18, 2, p. 131-138, 1990.

ZHU, Joe. Multi-factor performance measure model with an application to Fortune 500 companies. European Journal of Operational Research, 123, p. 105-124, 2000. 